frequently and incorrectly called $H$. attenuata. This name is no longer considered valid and the species should be known as Hydra vulgaris Pallas 1766. Another reason for confusion is that all the European species of hydra have been known by a plethora of names, most of which have been applied to more than one species. The unruly nomenclature has obscured the fact that there are rather few species of hydra and that these are easily distinguishable.

Similar general types of hydra occur on all continents, although the names and the number of species varies. $H$. oligactis and $H$. viridissima are cosmopolitan. In North America, $H$. littoralis and $H$. carnea among others, and in Japan, H. magnipapillata, closely resemble $H$. vulgaris of Europe. $H$. hymanae and $H$. utahensis from North America are similar to $H$. circumcincta. Whether some of these are synonyms is not yet known.

\section{Zoologisches Institut,}

THOMAS W. HOLSTEIN

Universität Munchen,

\section{D-8000 München 2, FRG}

Developmental Biology Center,

University of California, Irvine,

California 92717, USA

PierRe TaRdant

Zoologisches Institut, Universität Zürich, $\mathrm{CH}-8057$ Zürich, Switzerland

1. Tardent, P. Coelenterata. Cridaria. (ed. Seidel, F. Morphogenese der Tiere, L. 1: Al) 69-415 (Fischer, jena, 1978).

2. Lenhoff, H.M. (ed) Hydra: Research Methods (Plenum, New York, 1983).

3. Campbell, R.D. J. Linn. Soc. Lond. 91, 253-263 (1987)

4. Campbell, R.D. J. Linn. Soc. Lond. 95, 219-244 (1989)

5. Holstein, T.W. Hydrozoa (ed. Schwoerbel, R.J. Süsswas serfauna von Mitteleuropa 1.1), (Fisher, Stuttgart 1990).

\section{Tau marker?}

SIR-The Alz-50 monoclonal antibody recognizes a neuronal antigen, termed A68, exclusively in Alzheimer brain tissue $^{1}$. This antigen, of relative molecular mass $68,000(68 \mathrm{~K})$, is also detected in the cerebrospinal fluid $^{2}$ and in the olfactive epithelium from patients with Alzheimer's disease ${ }^{3}$, and it has been suggested that Alz-50 might help in vivo diagnosis. It was then shown that Alz-50 also crossreacts with tau proteins ${ }^{4}$, the main antigenic component of the paired helical filaments that accumulate in degenerating neurons during Alzheimer's disease, suggesting that A68 might be an aberrant form of tau. We have shown that two tau proteins of $M_{\mathrm{r}} 64$ and $69 \mathrm{~K}$, tau 64 and 69 , are specifically detected in brain areas affected by the neurofibrillary degeneration $^{5}$. These proteins arise from an abnormal phosphorylation of tau, as demonstrated by the decrease in their mass after alkaline phosphatase treatment $^{5}$. The crossreactivity of Alz-50 with tau proteins causes us to suspect that Tau 69 and A68 are the same protein.

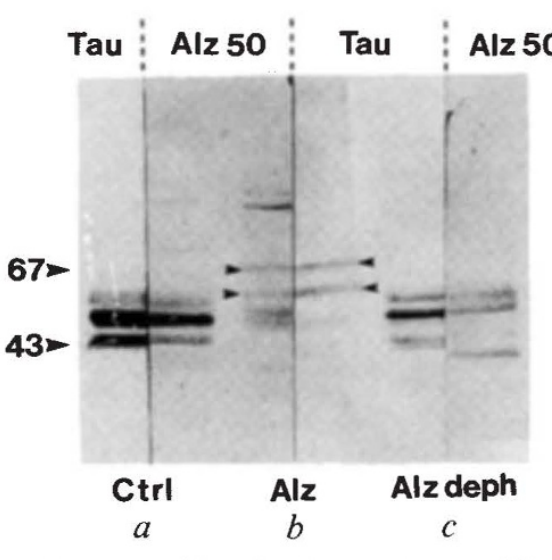

Binding of $\mathrm{Alz}-50$ and anti-tau on immunoblots of frontal cortex from a control (a) and a patient with Alzheimer's disease before $(b)$ and after $(c)$ alkaline phosphatase treatment. The dephosphorylation was performed as described in ref. 5 , and details are available on request from the authors.

Alz-50 was reacted against immunoblotted total protein extracts from different control and Alzheimer's brain areas. These immunoblots reveal that $\mathrm{Alz}-50$ is essentially directed against tau 64 and 69 (see figure) and that no protein other than the pathological tau proteins are detected in this molecular-mass range. The experimental dephosphorylation of tau 64 and 69 results in the formation of $50-60 \mathrm{~K}$ products, which are still labelled by Alz-50. Immunoblots of two-dimensionally resolved proteins corroborate these findings.

Our results strongly suggest that A68 is an abnormally phosphorylated tau protein. Because the expression of tau 69 / A68 is correlated with neurofibrillary degeneration and intellectual impairment $^{6}$, Alz-50 marker might be used to help diagnosis of the disease. Moreover, the further study of tau 69/A68 could help track the biochemical dysfunctions that lead to neuronal death and dementia.

STÉPHANE FLAMENT ANDRÉ DELACOURTE

\section{Laboratoire de Neurosciences,}

U156 INSERM,

Faculté de Médecine,

59045 Lille, France

1. Wolozin, B.L., Pruchnicki, A., Dickson, D.W. \& Davies, P.A. Science 232, 648-650 (1986).

2. Wolozin, B. \& Davies, P. Ann. Neurol, 22, 521-526 (1987).

3. Talamo, B.R. et al. Nature 337, 736-739 (1989).

4. Ksiezak-Reding, H., Binder, L.I. \& Yen, S. -H. J. biol. Chem 263, 7948-7953 (1988)

5. Flament, S., Delacourte, A., Hémon, B. \& Défossez, A. J. neurol. Sci 92, 133-141 (1989).

6. Flament, S. et al. Acta Neuropath. (in the press).

\section{Correction}

In the Commentary article "Duesberg, HIV and AIDS" (Nature 345, 659-660; 1990) it is said that homosexuals in the United States have a 900-fold higher risk of developing Kaposi's sarcoma. As stated in the same paragraph, the 900-fold higher incidence referred to HIV-positive homosexuals compared to HIVnegative homosexuals.

\section{Mutagen test}

SIR-It is commonly assumed that environmental mutagens are responsible for most mutations in germline and somatic cells, and that mutations arising through endogenous processes such as depurination, deamination, replication error and transposition are comparatively infrequent. With the development of direct sequencing methodology, enough mutational events can be examined to address this issue more directly. Mutagens should produce different mutation patterns in populations exposed to different environments, as each mutagen has its own fingerprint of mutation'. By contrast, endogenous processes could produce an essentially invariant pattern of mutation. I find the spectrum of germline mutations from a particular sample to be similar to the spectrum of somatic mutations associated with the p53 and retinoblastoma genes, suggesting that endogenous processes are dominant in these cancers. I propose that tumour-suppressor genes could be useful epidemiological tools for determining the exceptions where environmental mutagens do predominate.

A meaningful comparison of the pattern of mutation requires genes where the observed pattern faithfully reflects the underlying pattern of mutation. From a population-based study of Caucasian families with haemophilia $B$ residing in the midwestern United States and Canada (see table), we deduced ${ }^{2}$ that the observed mutations do approximate the underlying pattern (corrected for biases of mutant ascertainment) of recent germline mutations in factor IX. A similar pattern of mutation occurs in Asians ${ }^{3}$.

The tumour-suppressor genes offer an opportunity to examine the pattern of somatic mutation in vivo, without the artefacts induced by tissue culture. By contrast, dominant oncogenes, such as ras, are not good models for examining the pattern of spontaneous somatic mutation because only a few mutations will produce disease. Mutations in the p53 and retinoblastoma genes have recently been published (see table), and the pattern of somatic mutation in colon, brain, breast, and retina is similar to the pattern of germline mutation. Lung tumours are an exception to the general pattern $\left(P<10^{-1}\right)$; most cases occur in smokers, exposed to enormous amounts of inhaled mutagens.

These data suggest that the underlying

1. Suzuki, D.T., Griffiths, A.J.F., Miller, J.H. \& Lewontin, R.C. (eds) in An introduction to Genetic Analysis 333-335 (Freeman, New York, 1986).

2. Koeberl, D.D. et al. Am. J. hum. Genet. (in the press)

3. Baker, S.J. et al. Science 244, 217-221 (1989).

4. Bottema, C.D.K., Kettering, R.P., Yoon, H.-S. \& Sommer. S.S. Am. J. Hum. Genet. (in the press).

5. Nigro, J.M. et al. Nature 342, 705-708 (1989)

6. Yandell, D.W. et al. N. Engl. J. Med. 321, 1690-1695 (1989).

7. Takahashi, T. et al. Science 246, 491-494 (1989).

8. Iggo, R., Gatter, K., Bartek, J., Lane, D. \& Harris, A.L. Lancet 335, 675-679 (1990). 